\title{
工作機械の熱変形量推定に関する研究*
}

\author{
堀 三計*1, 西脇信彦*1, 石冨克也*2
}

\section{Study on Estimating Thermal Deformation of Machining System}

\author{
Sankei HORI, Nobuhiko NISHIWAKI and Katsuya ISHITOMI
}

\begin{abstract}
One of the machining errors is caused by thermal deformation of a machine tool. Thermal deformation is caused not only by inner heat sources such as bearings, motors and so on, but also by outer heat sources such as the room temperature variation in a machine shop. In general, when a unit power at the inner heat source is generated pulsewise or stepwise, the basic thermal deformation can be obtained analytically and experimentally. When the heating power in the source could be measured, it seems that the thermal deformation can be estimated using the basic deformation and the measured power. Therefore, the equivalent position of the inner heat source, the power generated at the source, the thermal deformation caused by the power, and so on are investigated in this study. As the results of this study, it is clarified that the thermal deformation can be estimated by measuring the temperature of the machine tool structure and that around it.
\end{abstract}

Key Words: Thermal Deformation, Phase Lag, Unit Power. Heat Flux, Surrounding Temperature Variation, Inverse Method

\section{1. 緒論}

機械部品の高精度化に伴い, 機械加工に於いても $\mu \mathrm{m}$ オダの加工精度が求められるようになってきた。 しかし, 現在のところ, 常時 $\mu \mathrm{mオ}$ オがの加工精度を 維持することは難しい. その主な原因として工作機械 の熱変形が挙げられる。熱変形の原因としては, モー 夕や軸受などの内部熱源, 室温の変化などの外部熱源 及び切削熱などが考えられ，それらの原因による熱変 形に関しては古くから研究が行われている (1) (5).

最近の研究 ${ }^{(6)(7)}$ では, 工作機械構造の熱変形量とそ の代表温度との関係をニューラルネットワークを用い て予め実験的に求めておき, 加工中に測定された代表 温度の値から工作機械の熱変形量を補正する方法が提 案されている。しかし，この方法では代表温度の測定 位置が経験と勘により決められ，温度測定位置により その補正精度が影響を受ける。従って, 工作機械内部 の熱の流れを十分考虑した温度測定を行う必要がある と思われる。

そこで本研究では, 工作機械内部の各熱源における

* 原稿受付 1996 年 3 月 11 日.

*1 正員, 東京農工大学工学部 (184 小金井市中町 2-24-16).

*2 東京農工大学大学院 [現：(株) 日立製作所システム事業部 (恶101 東京都千代田区神田駿河台 4-6)].
発熱量と工作機械の熱変形量の関係を明らかにし，工 作機械の熱変形量を補正する方法について数值解析に より検討した。具体的には，各熱源でステップ状又は パルス状の発熱が生じたとき, その発熱量と工作機械 構造内の温度変化及び工作機械の熱変形量の関係を明 らかにし，それらの関係を用いて逆に工作機械内部の 温度変化より内部熱源における発熱量を求め, その発 熱量をもとに熱変形量を予測する方法について検討を 行った。その際に, 周囲の温度変化に伴う熱変形や工 作機械内部の複数熱源の影響についても検討を行った.

\section{2. 熱源位置の探査}

工作機械では一般にモータや軸受などで熱が発生し て，その熱変形が生じることが知られている.しかし，

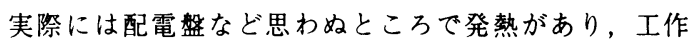
機械の熱変形がその発熱の影響を受けることがある. そこで, 工作機械内部の熱源位置を求める方法につい て検討した。すなわち，駆動モー夕の回転数を正弦波 状または矩形波状に変化させて工作機械内部の発熱量 を変動させ，それにより熱源周辺の温度を変動させて， 熱源の位置を求める方法について検討した。ここで, 半無限固体の表面から式(1)に示すような正弦波状に変 化した熱が流入すると, 表面から距離 $X$ の位置の温度 
変動は式(2)で示されるようになる，そこで, 工作機械 内部の熱源での発熱を变動させ, 工作機械内部の温度 変動を測定すれば, 地震の震源地探查のように熱源の 位置や発熱量を逆に求めることができると考えられる。

$$
\begin{aligned}
q & =q_{0}+q^{\prime} \sin (\omega t) \\
T & =\left[\begin{array}{ll}
q^{\prime} \cdot \exp (-k \cdot X) / \sqrt{2} & \lambda \cdot k
\end{array}\right] \sin (\omega t-k \cdot X-\pi / 4) \\
k & =(\omega / 2 a)^{0.5}
\end{aligned}
$$

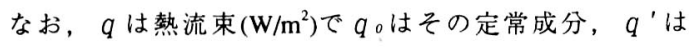

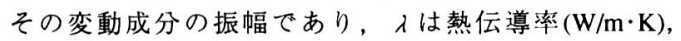

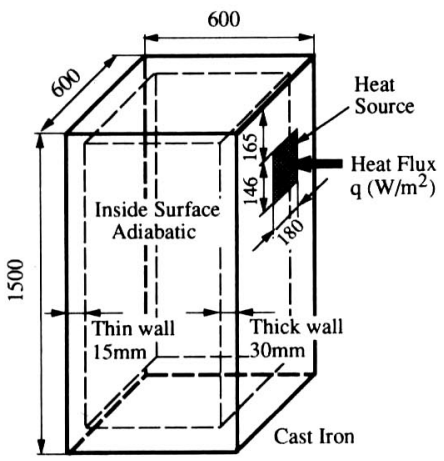

Heat Transfer Coefficient : $10 \mathrm{~W} / \mathrm{m}^{2} \cdot \mathrm{K}$

Fig. 1 Hollow column model of a machining center

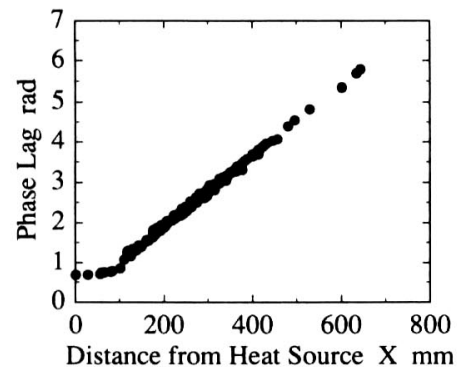

Fig.2 Relationship between phase lag and distance from heat source

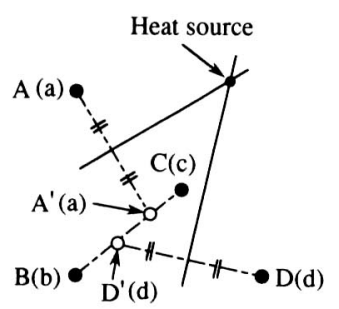

( ):Phase lag

Fig.3 Researching method of heat source location $\omega$ は周期 $(\mathrm{rad} / \mathrm{s}), \quad a$ は熱拡散率 $\left(\mathrm{m}^{2} / \mathrm{s}\right), X$ は表面からの 距離 $(\mathrm{m}), t$ は時間 $(\mathrm{s}), k \cdot X$ は表面から距離 $X$ の位置 の温度変動と半無限固体表面に流入する熱量変動の間 の位相である。

実際の工作機械構造のコラムをモデル化して図1に 示すような中空コラムを考えた. その表面の一部に, 正弦波状に土131.4Wの熱量 $\left(0.5 \mathrm{~W} / \mathrm{cm}^{2}\right.$ の熱流束) が流 入し，その外表面の熱伝達率を $10 \mathrm{~W} / \mathrm{m}^{2} \cdot \mathrm{K}$ とし, 内表 面を断熱とした場合について，その温度変動を数値計 算により検討した，具体的には，熱源の中心から温度 測定位置までの最短距離 $X$ とその点における温度と流 入熱量の間の位相 $(\omega / 2 a)^{0.5} X$ の関係を調べた。その 結果を図2に示す。同図より位相 $(\omega / 2 a)^{0.5} X$ の值がわ かれば熱源までの最短距離 $X$ が求められることがわか る. 従って, 四3に示すように, 任意の4点(A，B， C , D)におけるそれぞれの位相を $a, b, c, d$ と し，点 $\mathrm{B}$ と点 $\mathrm{C}$ 間で位相が熱源からの距離に比例して 変化すると仮定して, 点 $\mathrm{A}$ 及び点 $\mathrm{D}$ と同位相の点 $\mathrm{A}$ 及

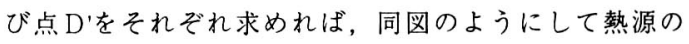
位置を求めることができる，また，この方法は，複数 の熱源がある時でもおのおの異なる周期で発熱してい る場合には，周波数解析を行うことにより，熱源を分 離して探查できる。さらに，同じ周期で同位相で発熱 している場合でも，それぞれの熱源極近傍で再度その 位置を探査すれば分離して測定することができる。

\section{3．変動温度と流入熱量の関係}

3. 1 热源近傍の温度工作機械のような複 雑形状の場合, 温度変動より逆に流入熱流束を求める 方法 ${ }^{(8)}$ は確立されていない。そこで本研究では，その 逆算方法について検討した，具体的には，図4に示す ような中実角柱 $(60 \mathrm{~mm} \times 60 \mathrm{~mm} \times 100 \mathrm{~mm})$ の一方の端面 から熱が流入し，その他の面で放熱（熱伝達率 $=10 \mathrm{~W} / \mathrm{m}^{2}$ ·K）している場合を考えた。なお，角柱の材質はね ずみ鋳鉄とし，差分法で計算を行った。

図5(a)に示すように，パルス状熱流束 $q_{p}(t)(0<$

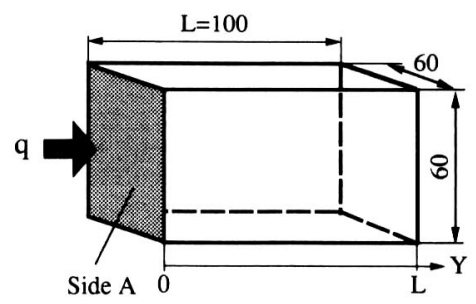

Fig.4 Model of solid column 
$t \leqq \Delta t$ で $q_{p}(t)=q_{p 0}, \quad t \leqq 0$ 及び $\Delta t<t$ では $q_{p}(t)$ $=0$. 但し, $q_{p o}=$ 一定, $t$ は時間, $\Delta t$ はパルス幅 $)$ が中実角柱の端面 A から流入したとき，流入面近傍の

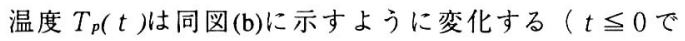
$\left.T_{p}(t)=0\right)$. なお, 本研究では $T_{p}(t)$ のことを温度特 性データと呼ぶことにする.

次に, 同じ角柱端面へある任意の熱流束 $q(t)$ が流 入し, その流入面近傍の温度 $T(t)$ が同図(c)の点線の ように変化したとき, その温度 $T(t)$ は温度特性デー 夕 $T_{P}(t)$ を用いた同図(c)の実線及び式(3)に示すように 近似的に表すことができる。熱流束 $q(t)$ は，式(3)で 求まった係数 $\alpha_{1}, \alpha_{2}, \cdots, \alpha_{n}, \cdots$ 式(4)へ代入し て求めることができる。すなわち, 熱源近傍の温度を 測定することにより流入熱流束を求めることができる。 なお，本研究では係数 $\alpha$ を補正係数と呼ぶことにする.

$T(t)=\alpha_{1} T_{p}(t)+\alpha_{2} T_{p}(t-\Delta t)+\cdots \cdot+\alpha_{n} T_{p}(t-(n-1) \Delta t)+\cdots$

$q(t)=\alpha_{1} q_{p}(t)+\alpha_{2} q_{p}(t-\Delta t)+\cdots+\alpha_{n} q_{p}(t-(n-1) \Delta t)+\cdots$

上記方法を確認するため, 図4の角柱端面 A から $q(t)=10+5 \cdot \sin (2 \pi t / 60) \mathrm{kW} / \mathrm{m}^{2}$ の熱流束が流入したと

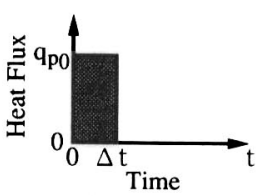

(a) Pulselike heat flux

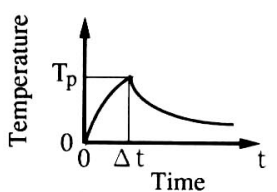

(b) Temperature

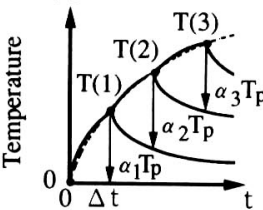

Time

(c) Temperature

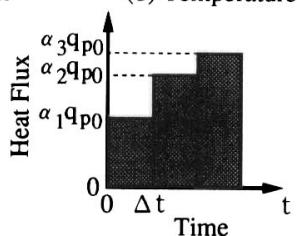

(d) Heat flux
Fig.5 Inverse conduction method

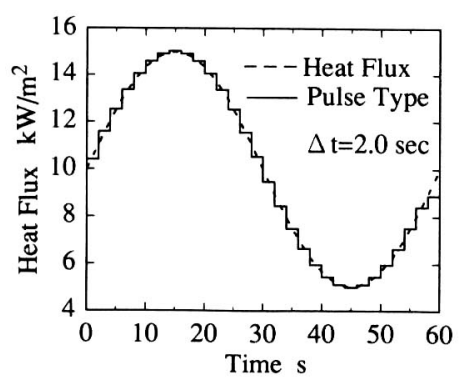

Fig.6 Estimated heat flux using pulselike heat flux
き, 端面 $\mathrm{A} の$ 温度を数值解析で求めると同時に, 時間 幅2.0秒のパルス状熱流束が流入したときの温度特性デー 夕も同時に求め, その温度特性デー夕より逆に流入熱 流束を求めた。その結果を図6に示す。同図に示すよ うに熱源近傍の温度変化より流入熱量を求めることが できたが，より精度を向上させるには，近似するパル ス波の時間幅を小さくするか，又は図7に示すように パルス状流入熱量と三角波状流入熱量を組み合わせた 台形波状の流入熱流束で近似する方法が考えられる. 後者の方法を用いる場合は，図7に示すようにパルス 時間幅 $\Delta t$ における端面 $\mathrm{A}$ の温度 $T$ ：を測定する他に， その半分の時間 $\Delta t / 2$ に扔ける端面 $\mathrm{A}$ の温度 $T_{0.5}$ 測 定し，式(5)と式(6)により補正係数 $\alpha ， \beta$ を求める。そ の補正係数の值と式(7)により，台形波状の流入熱流束 を近似することができる。

$$
\begin{aligned}
& T_{l}=\alpha T_{p l}+\beta T_{t l} \\
& T_{0.5}=\alpha T_{p 0.5}+\beta T_{t 0.5} \\
& q(t)=\alpha q_{p 0}+\beta\left(q_{t 0} / \Delta t\right) t
\end{aligned}
$$

従って, 端面 $\mathrm{A} の$ 温度を上記の手法で近似すると, 式(8)の様な近似式が得られる. その結果, 図7に示す 熱流束 $q_{p}(t), q t(t)$ と式(9)より流入熱流束を求める ことができる。

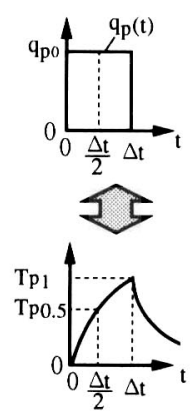

(a)

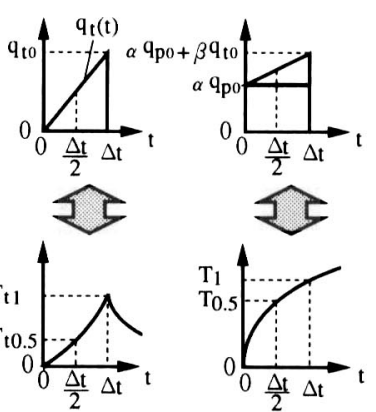

(b)

(c)
Fig.7 Accurate estimation method

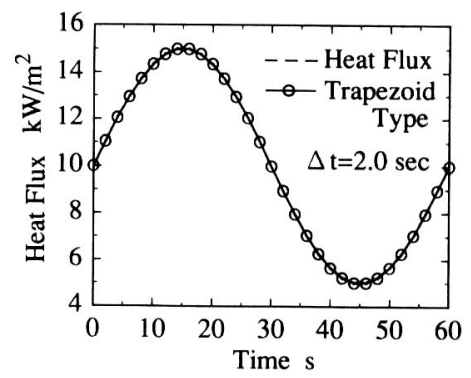

Fig.8 Estimated heat flux using trapezoid heat flux 


$$
\begin{gathered}
T(t)=\alpha_{l} T_{p}(t)+\beta_{l} T_{t}(t)+\alpha_{2} T_{p}(t-\Delta t)+\beta_{2} T_{t}(t-\Delta t)+ \\
\cdots \cdots+\alpha_{n} T_{p}(t-(n-1) \Delta t)+\beta_{n} T_{t}(t-(n-1) \Delta t)+\cdots \cdot \\
q(t)=\alpha_{1} q_{p}(t)+\beta_{l} q_{t}(t)+\alpha_{2} q_{p}(t-\Delta t)+\beta_{2} q_{t}(t-\Delta t)+ \\
\cdots \cdots+\alpha_{n} q_{p}(t-(n-1) \Delta t)+\beta_{n} q_{t}(t-(n-1) \Delta t)+\cdots \cdot
\end{gathered}
$$

図4の角柱の端面から図6の場合と同じ熱流束が流入 し，パルス時間幅 $\Delta t$ を同じく2.0秒として，台形波状 の流入熱流束で近似すると, 図8に示すような近似解 が得られた。その結果, 図6のパルス状近似より近似 精度を向上することができた。

\section{2 蕉源から遠い位嘈の温度 熱流束 $q_{p 0}$} がステップ状に熱源から流入したとき，熱源から離れ た点で測定した温度と前述のパルス波近似を用いて流 入熱流束を求めた。具体的には，図4のモデルを用い て熱流入面からの距離 $X$ と近似のパルス時間幅 $\Delta t$ を 変化させて流入熱流束 $q(t)$ を求めた。 その結果, $X$ の值が大きくなると又は $\Delta t$ の值が小さくなると, 得 られた熱流束の値がハンチングを起こした。そこでそ の得られた熱流束の最大值を $q_{\text {max }}$ と, 流入熱流束 $q_{p 0}$ で無次元化して, 次式のフーリ工数Frとの関係を調べた.

$$
F r=\mathrm{a} \cdot \Delta t / X^{2}
$$

ここで， $a$ は熱拡散淬 $\left(\mathrm{m}^{2} / \mathrm{s}\right), X$ は熱流入面からの距離 $(\mathrm{m})$ である。図9に示されるようにフーリエ数が 0.3 以上で あれば，本方法で逆算した熱流束值が実際に流入した 值と一致することが分かった。

そこで，近似するパルス時間幅が小さいためフーリ 工数が 0.3 以下になる場合は，予めフーリ工数が 0.3 以 上となるパルス時間幅で求めてから，そのパルス時間 幅を小さくする方法が考えられる，具体的には，熱流 束 $q_{p 0}$ でパルス幅 $2 \Delta t$ のパルス状熱流束 $q_{2 p}(t)$ が流入 したときの温度特性デー夕 $T_{2 p}(t)$ を予め求めておき，次 式のようにして補正係数 $\alpha 2^{\prime}, \alpha 4^{\prime}, \cdots, \alpha{ }_{2 n}^{\prime}$ を求め,さ らに求まった補正係数と 2 倍のパルス時間幅の熱流束

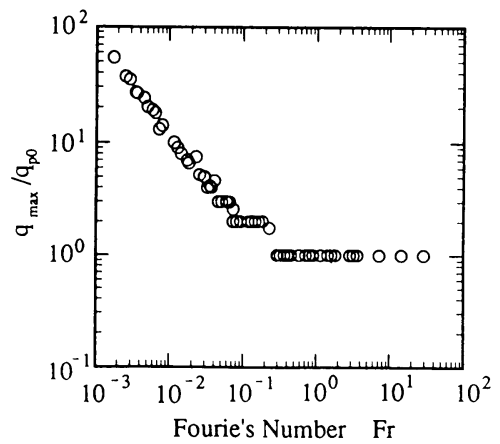

Fig.9 Relationship between Fourie's number and $q_{\max } / q_{p} 0$ $q_{2 p}(t)$ を式(12)に代入することにより流入熱流束 $q(t)$ が求められる.

$$
\begin{aligned}
& T(2 \Delta t)=\alpha_{2}^{\prime} T_{2 p}(2 \Delta t) \\
& T(4 \Delta t)=\alpha_{2}^{\prime} T_{2 p}(4 \Delta t)+\alpha_{4}^{\prime} T_{2 p}(2 \Delta t) \\
& T(6 \Delta t)=\alpha_{2}^{\prime} T_{2 p}(6 \Delta t)+\alpha_{4}^{\prime} T_{2 p}(4 \Delta t)+\alpha_{6}^{\prime} T_{2 p}(2 \Delta t) \\
& T(2 n \Delta t)=\alpha_{2}^{\prime} T_{2 p}(2 n \Delta t)+\alpha_{4}^{\prime} T_{2 p}((2 n-2) \Delta t)+\cdots \cdot \\
& +\alpha_{2 n}^{\prime} T_{2 p}(2 \Delta t) \\
& q(t)=\alpha_{2}^{\prime} q_{2 p}(t)+\alpha_{4}^{\prime} q_{2 p}(t-2 \Delta t)+\alpha_{6}^{\prime} q_{2 p}(t-4 \Delta t)+\cdots \\
& +\alpha_{2 n}^{\prime} q_{2 p}(t-(2 n-2) \Delta t)
\end{aligned}
$$

次に熱流束 $q_{p 0}$ でパルス時間幅 $\Delta t$ のパルス状熱流 束 $q_{p}(t)$ が流入したときの温度特性デー夕 $T_{p}(t)$ を予 め求めておき, 式(11)で求められた補正係数 $\alpha 2 n^{\prime}$ を式 (13)のようにパルス幅 $\Delta t$ のときの補正係数 $\boldsymbol{\alpha}_{\mathrm{n}}$ へ代入 する. 求まった補正係数 $\alpha_{\mathrm{n}}$ を式(14)の左辺へ代入して, 新たに補正係数 $\alpha$ から $\alpha 2 \mathrm{n}$-1迄を求め, さらに式(15)よ り $\alpha{ }_{2 \mathrm{n}}$ の值を求める. しかし, 新たに求めた補正係数 と代入した補正係数の值とが異なる場合は, 新たに求 められた補正係数を用いて同様な計算を行い，両者の 值がほほ等しくなるまでこの計算を繰り返す。最終的 に求められた補正係数を真の補正係数として 式(16)より流入する熱流束 $q(t)$ が求められる.

$$
\boldsymbol{\alpha}_{2}=\alpha_{2}^{\prime}, \boldsymbol{\alpha}_{3}=\alpha_{4}^{\prime}, \boldsymbol{\alpha}_{4}=\alpha_{4}^{\prime}, \cdots \cdots \cdots, \boldsymbol{\alpha}_{2 n-1}=\alpha_{2 n}^{\prime}, \boldsymbol{\alpha}_{2 n}=\alpha_{2 n}^{\prime}
$$

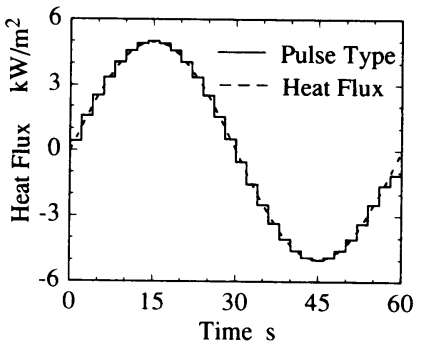

(a) $\Delta t=2.0 \mathrm{~s}$

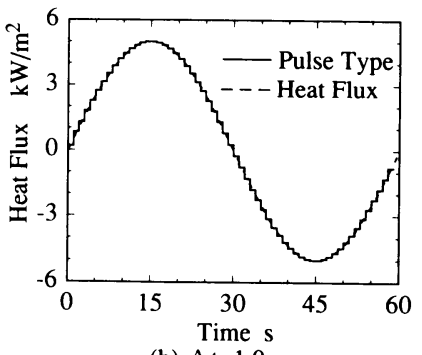

(b) $\Delta \mathrm{t}=1.0 \mathrm{~s}$

Fig.10 Estimated heat flux from long distance 
$T(2 \Delta t)-\alpha_{2} T_{p}(\Delta t)=\alpha_{1} T_{p}(2 \Delta t)$

$T(3 \Delta t)-\alpha_{3} T_{p}(\Delta t)=\alpha_{1} T_{p}(3 \Delta t)+\alpha_{2} T_{p}(2 \Delta t)$

$T(4 \Delta t)-\alpha_{4} T_{p}(\Delta t)=\alpha_{1} T_{p}(4 \Delta t)+\alpha_{2} T_{p}(3 \Delta t)+\alpha_{3} T_{p}(2 \Delta t)$

$T(2 n \Delta t)-\alpha_{2 n} T_{p}(\Delta t)=\alpha_{1} T_{p}(2 n \Delta t)+\alpha_{2} T_{p}((2 n-1) \Delta t)$

$+\alpha_{3} T_{p}((2 n-2) \Delta t)+\cdots \cdots+\alpha_{2 n-1} T_{p}(2 \Delta t)$

$\alpha_{2 n}=\alpha_{2 n-1}+\left(\alpha_{2 n-1}-\alpha_{2 n-2}\right)$

$q(t)=\alpha_{1} q_{p}(t)+\alpha_{2} q_{p}(t-\Delta t)+\alpha_{3} q_{p}(t-2 \Delta t)$

$+\alpha_{4} q_{p}(t-3 \Delta t)+\cdots+\alpha_{2 n-1} q_{p}(t-(2 n-2) \Delta t)$

$+\alpha_{2 n} q_{p}(t-(2 n-1) \Delta t)$

実際に，図4の角柱の端面 $\mathrm{A}$ から図6の場合と同じ熱流 束が流入したときについて，熱流入面から $12 \mathrm{~mm}$ の位 置の温度を用いて，流入熱流束を上記の方法で逆算し た。その結果を図10に示すように，パルス時間幅 $\Delta t$ が2秒のときょりも1秒としたときの方が近似精度 が良くなっていることがわかる。なお，パルス幅を小 さくすれば近似精度をさらに向上できる.

\section{4. 多重熱源の場合の流入熱量の算出}

一般に工作機械構造内部には複数の熱源がある。そ こで, 複数の熱源がある場合についての流入熱流束の 算出方法について検討した。例えば, 二カ所に熱源 $\mathrm{A}$ とBがあり，単位面積当たり熱量 $q_{A}(t)$ と $q_{B}(t)$ がそ れぞれで発生している場合, それぞれの熱源近傍の温 度 $T_{A}(t)$ と $T_{B}(t)$ は両熱源の影響を受ける。 そこで, 熱 源Aでパルス状の発熱 $q A p(t)$ があるとき, その発熱に より生じる熱源 $\mathrm{A} 及 ひ ゙ \mathrm{~B} の$ 近傍の温度特性デー夕をそ れぞれ $T_{A p}(t)$ と $T_{A p}{ }^{\prime}(t)$ とし, 同様に熱源 $\mathrm{B}$ でパルス

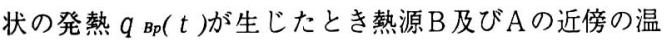
度特性デー夕をそれぞれ $T_{B p}(t)$ と $T_{B p}{ }^{\prime}(t)$ とすると, 各 熱源近傍の温度 $T_{A}(t)$ と $T_{B}(t)$ は式(17)のようになる. 同式より補正係数 $\alpha_{\mathrm{A} 1}, \alpha_{\mathrm{A} 2}, \cdots, \alpha_{\mathrm{An}}, \alpha_{\mathrm{B} 1}, \alpha_{\mathrm{B} 2}$, $\cdots, \alpha \mathrm{Bn}$, を求め, 式(18)に代入すると各熱源の発熱

量 $q_{A}(t)$ と $q_{B}(t)$ を求めることができる.

$$
\begin{aligned}
T_{A}(t) & =\alpha_{A 1} T_{A p}(t)+\alpha_{A 2} T_{A p}(t-\Delta t)+\alpha_{A 3} T_{A p}(t-2 \Delta t) \\
& +\alpha_{A 4} T_{A p}(t-3 \Delta t)+\cdots \\
& +\alpha_{B 1} T_{B p}^{\prime}(t)+\alpha_{B 2} T_{B p}^{\prime}(t-\Delta t)+\alpha_{B 3} T^{\prime}{ }_{B p}(t-2 \Delta t) \\
& +\alpha_{B 4} T_{B p}^{\prime}(t-3 \Delta t)+\cdots \\
T_{B}(t) & =\alpha_{B 1} T_{B p}(t)+\alpha_{B 2} T_{B p}(t-\Delta t)+\alpha_{B 3} T_{B p}(t-2 \Delta t) \\
& +\alpha_{B 4} T_{B p}(t-3 \Delta t)+\cdots \\
& +\alpha_{A 1} T^{\prime}{ }_{A p}(t)+\alpha_{A 2} T^{\prime}{ }_{A p}(t-\Delta t)+\alpha_{A 3} T^{\prime}{ }_{A p}(t-2 \Delta t) \\
& +\alpha_{A 4} T^{\prime}{ }_{A p}(t-3 \Delta t)+\cdots \\
q_{A}(t) & =\alpha_{A 1} q_{p}(t)+\alpha_{A 2} q_{p}(t-\Delta t)+\alpha_{A 3} q_{p}(t-2 \Delta t) \\
& +\alpha_{A 4} q_{p}(t-3 \Delta t)+\cdots \cdot \\
q_{B}(t) & =\alpha_{B 1} q_{p}(t)+\alpha_{B 2} q_{p}(t-\Delta t)+\alpha_{B 3} q_{p}(t-2 \Delta t) \\
& +\alpha_{B 4} q_{p}(t-3 \Delta t)+\cdots \cdots
\end{aligned}
$$

なお，多数の熱源がある場合も上記と同様な方法を用 いることにより求めることができる.

\section{5. 熱変形量の推定}

工作機械の熱変形を推定するため，図11に示すよう な立フライス盤のモデルを用いた。 その構造内部には， 主軸モータ, 主軸軸受け部, 切削点, ボールネジ部な どの熱源 (図中参照) があり，加工時にのみ発熱する こととした。具体的には, 工作機械構造内で図12(c)に 示すように，表1で示される発熱 $Q_{m}$ が3分間あり，そ の半分の発熱が次の3分間あり, その後の3分間は無発 熱とし,この発熱周期が繰り返されるとした。 なおそ の際に主軸の回転数が変化するとして, 主軸端面, 工 具外周面, 工作物上面の熱伝達率 $h$ aが発熱の変化と 伴に同図(d)のように変化するとした，さらに，同図(a) のように，加エスケジュールにそって加エサイクルが 停止し, 工作機械内部の発熱も停止するとした。さら に，周囲の温度も同図(b)に示すように変化するとした。

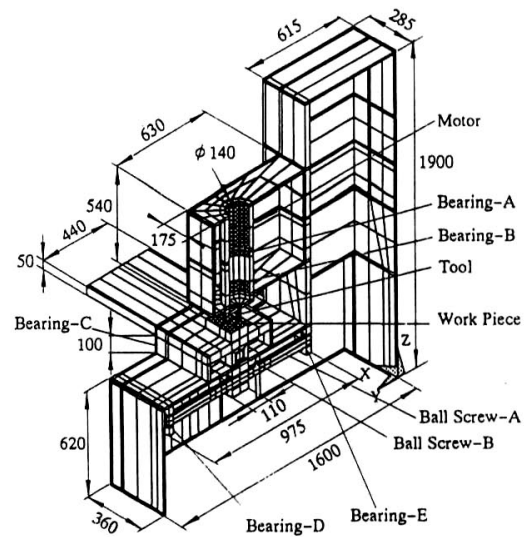

Fig.11 Machine tool model

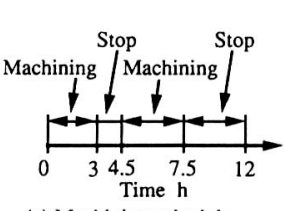

(a) Machining schedule

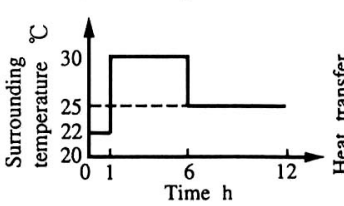

(b) Variatuon of surrounding temperature

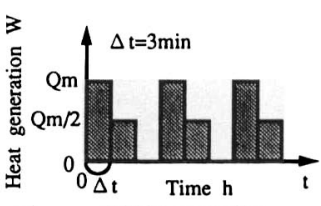

(c) Het generation

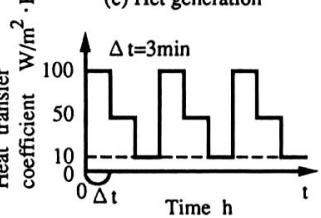

(d) Local heat transfer coefficient
Fig.12 Machining schedule and thermal condition of the machine tool 
Table 1 Heat generation at the inner heat sources $Q m$

\begin{tabular}{|c|c|c|c|}
\hline Heat source & $\begin{array}{c}\text { Heat generation } \\
{[\mathrm{W}]}\end{array}$ & Heat source & $\begin{array}{c}\text { Heat generation } \\
{[\mathrm{W}]}\end{array}$ \\
\hline Motor & 250 & Bearing-A & 50 \\
\hline Tool & 120 & Bearing-B & 100 \\
\hline Work Piece & 120 & Bearing-C & 10 \\
\hline Ball Screw-A & 10 & Bearing-D & 10 \\
\hline Ball Screw-B & 20 & Bearing-E & 10 \\
\hline
\end{tabular}

上述のような境界条件のもとで有限要素法により工 作機械構造内部の温度分布, 特に各熱源近傍の温度 $T i(t)$ を求めた。また同時に工具・工作物間の熱変形 量 $\delta(t)$ も求めた。一方，3分間のパルス状発熱が各熱 源で個別に生じたときの各熱源近傍の温度特性データ $T i p(t)$ と工具・工作物間の熱変形特性デー夕 $\delta i p(t)$ を予め求め, さらには構造周辺の温度 $T s$ が $20^{\circ} \mathrm{C}$ から $21^{\circ} \mathrm{C}$ に変化したときの工具・工作物間の熱変形特性デー

夕 $\delta T s(t)$ についても予め求めた.

そこで, 各熱源の $T i(t)$ の值を各熱源の温度特性デー 夕 $T i p(t)$ を用いて近似し, 各熱源毎の補正係数を求め た。その補正係数と熱変形特性デー夕 $\delta i p(t)$ とを用い て, 構造内部での発熱による熱変形量 $\delta Q(t)$ を求めた. さらに, 周囲温度変化に伴う熱変形量 $\delta s(t)$ を次式に より求めた。

$$
\delta_{S}(t)=2 \delta_{T S}(t)+8 \delta_{T S}(t-1(h))-5 \delta_{T S}(t-6(h))
$$

従って, 両者の和 $(\delta Q(t)+\delta s(t))$ より求めた熱変 形量 $\delta Q+s(t)$ と直接境界条件を用いて求めた熱変形量 $\delta(t)$ と比較検討した.

その結果, 工作物上面の中心から離れる方向を負と すると，工作物工具間の相対熱变形量は図13に示すよ うになり，各特性デー夕から求めた結果は，同図点線 で示される数值解析結果とよく一致することが明らか となった。従って，本方法により熱変形量を推定でき

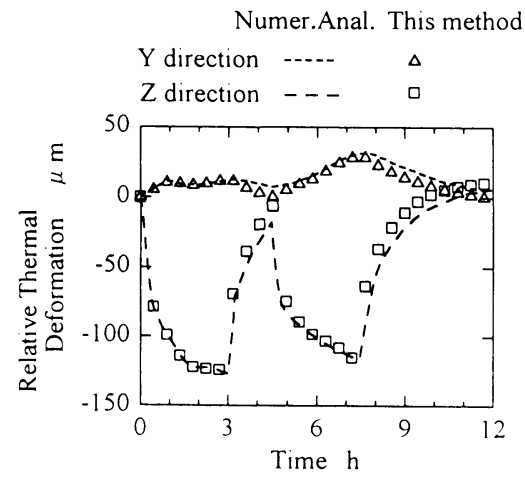

Fig.13 The composite relative thermal deformation
ることが明らかとなった。

なお，本方法の応用として，実験的に特性デ一夕を 求める方法がある。具体的には，一定条件のもとで工 作機械を運転したときの熱変形挙動とそのときに熱源 近傍の温度变化を測定して，それらを特性デー夕とす る。さらに, 実際の加工時の熱源近傍の温度変化を測 定して温度特性データで近似したときの補正係数から 熱変形量を予測することができる。その際に工作機械 を運転しない状態で周辺温度変化に伴う熱変形の特性 ベースも求めて，周囲の温度変化による熱変形量を実 験的に予測することができると考えられる。

\section{6. 結論}

本研究では, 工作機械の熱変形挙動を推定する方法 について研究を行った。その結果，以下のことが明ら かとなった。

(1)工作機械内部の発熱を変動させることにより，その 熱源の位置を求めることができた。

(2)単位熱量がパルス状に流入したときに，熱源近傍の 温度特性デー夕を予め求めておけば，任意の熱量が流 入したときその流入熱量を補正係数を用いて求めるこ とができた。すなわち，熱伝導の逆問題を求めること が出来た。

(3)工作機械内部の熱源近傍の温度挙動と周囲の温度変 化を測定すれば，熱変形特性デー夕を用いて工作機械 の熱変形挙動を推定できた。

なお，特性デー夕は数值解析からだけではなく，実 験的に求めることができるので，その実験による特性 デー夕を用いて熱変形量が推定できると思われる。

\section{文献}

(1)T.SATA, et. al. , MACHINE TOOL DESIGN AND RESERCH Vol.16, 1975, 203-208

(2)M.A.Mannan and S.Broms, CIRP, 1992, 451-454 (3)是田, 他 4 名, 精密工学会誌, 60-5(1994), 652-656. (4)是田, 他 3 名, 精密工学会誌, 60-6(1994), 853-857. (5)中村, 他 3 名, 精密工学会誌, 60-7(1994), 979-983. (6)森脇 - 趙, 機論, 58-550, C (1991), 1932-1937. (7)森脇，他 2 名，機論，61-584, C(1995), 1691-1696. (8)庄司，機論，44-381，(1978)，1633-1643. 